\title{
Efficacy of Locally Isolated Lactic Acid Bacteria Against Antibiotic-Resistant Uropathogens
}

\author{
Asma Manzoor, ${ }^{1, *}$ Ikram Ul-Haq, ${ }^{1}$ Shahjhan Baig, ${ }^{2}$ Javed Iqbal Qazi, ${ }^{3}$ and Sanja Seratlic ${ }^{4}$ \\ ${ }_{1}^{1}$ Institute of Industrial Biotechnology, Government College University, Lahore, Pakistan \\ ${ }_{3}^{2}$ Food and Biotechnology Research Center, PCSIR Labs Complex, Lahore, Pakistan \\ 3 Department of Zoology, University of the Punjab, Lahore, Pakistan \\ ${ }^{4}$ Teagasc Food Research Center, Moorepark, Fermoy, Co. Cork, Ireland
Tertant \\ *Corresponding author: Asma Manzoor, Institute of Industrial Biotechnology, Government College University, Lahore, Pakistan. Tel:+92-3214548913, E-mail: asmamanzoor33@hotmail.com
}

Received 2014 March 15; Revised 2014 June 14; Accepted 2014 June 28.

\begin{abstract}
Background:Antibiotic resistance represents a serious global health threat to public health, so infections such as pneumonia and urinary tract infection (UTI) are becoming harder to treat. Therefore, it is necessary to develop an action plan to restrain the problem of antibiotic resistance. One approach in UTI control could be the use of lactobacilli because these indigenous inhabitants in human intestine have been found to play an important role in protecting the host from various infections.

Objectives: We sought to check the efficacy of locally isolated Lactobacillus species to eradicate antibiotic-resistant pathogenic bacteria causing UTI.

Materials and Methods: Lactic acid bacteria isolated from spoiled fruits and vegetables and grown in MRS medium were screened against multi-drug-resistant Candida albicans, Klebsiella pneumoniae, Pseudomonas aeruginosa, Escherichia coli, and Enterococcus fecalis.

Results: Fifty-four lactic acid bacteria were isolated from spoiled fruits and vegetables, of which 11 Gram-positive and catalase-negative Lactobacillus isolates were identified by carbohydrate assimilation profiles as Lactobacillus acidophilus, L. paracasei, L. delbrueckii, L. casei, $L$. helveticus, L. brevis, L. salivarius, L. fermentum, L. rhamnosus, L. animalis, and L. plantarum. The latter organism had the highest abundance of all the samples, so its isolates were also verified through $16 \mathrm{~S}$ rRNA gene sequencing. The isolated Lactobacilli were screened against multidrug-resistant uropathogens, viz. C. albicans, P. aeruginosa, K. pneumoniae, E. fecalis, and E. coli. The growth inhibition zone (GIZ) was over $10 \mathrm{~mm}$ against all the uropathogenic test organisms, where L. fermentum and L. plantarum strains demonstrated remarkable inhibitory activities against $E$. coli and $E$. faecalis, with a GIZ up to $28 \mathrm{~mm}$. The susceptibility test to 16 antibiotics showed multidrug resistance (3 to 5 antibiotics) among all the tested uropathogens.

Conclusions: The obtained results revealed that all the Lactobacillus isolates displayed antimicrobial activity against 6 out of 7 antibioticresistant uropathogens, indicating that these bacteria could represent a good ecological plan for the control and prevention of UTI.
\end{abstract}

Keywords: Urinary Tract Infections, Antibiosis, Antibiotics Resistance

\section{Background}

The major cause of infectious and emerging epidemiological diseases e.g. nausea, vomiting, abdominal cramps, and diarrhea among the inhabitants of Pakistan is the consumption of microbiologically contaminated food and extensive use of antibiotics (1). Urinary tract infection (UTI) is the most common bacterial infection in humans. UTI is a major health problem not only in developing countries but also in Europe and North America (2) and is defined as the common inflammation of the urinary system, which includes the kidney, bladder, and urethra. This infection may be called bladder infection or simply cystitis when it affects the lower urinary tract or may be called kidney infection or pyelonephritis when it affects the upper urinary tract. In human intestine, Escherichia coli and staphylococci are normal inhabitants and major causative agents for these types of uncomplicated infections (3).
The recommended prevention for UTI should be proper hygiene of the genital area. Genital and bladder infections increase due to the depletion or distraction of normal urogenital microflora, in particular Lactobacillus species as the most prevalent bacteria in healthy humans. The growing resistance of pathogenic bacteria to antibiotics requires the development of an alternative method to prevent and treat urogenital infections. Multidrug resistance of uropathogens has been attributed to commonly used antibiotics, including ampicillin, ciprofloxacin, trimethoprim-sulfamethoxazole, quinolones, etc. (4). On the other hand, vancomycin and teicoplanin have been found active against most Gram-positive bacteria, while some lactobacilli have been found to be resistant to these glycopeptides (5). Possible prophylactic effects of Lactobacillus strains against experimental E. coli

Copyright (C) 2016, Ahvaz Jundishapur University of Medical Sciences. This is an open-access article distributed under the terms of the Creative Commons Attribution-NonCommercial 4.0 International License (http://creativecommons.org/licenses/by-nc/4.0/) which permits copy and redistribute the material just in noncommercial usages, provided the original work is properly cited. 
infections and the use of such strains for the prevention of human urogenital infections have been described in numerous preclinical and clinical reports (6).

In addition, the center for disease control (CDC) reported that UTI represents more than $30 \%$ of acute care in hospitals. With the increasing bacterial resistance against antibiotics and drug adverse effects, the alternative strategies such as the use of probiotics, prebiotics, and immunostimulants have been considered for disease control (7). To date, most probiotics proposed belong to the group of lactic acid bacteria (LAB). These bacteria have been reported as friendly bacteria which normally colonize human digestive, urinary, and genital systems and rarely cause any infection. In addition, LAB lack pathogenicity and confer health benefits such as reduction in the level of serum cholesterol, improvement of the gastrointestinal function, enhancement of the immune system, and reduction in the risk of colon cancer (8). Also, LAB are able to inhibit exogenous pathogens by prohibiting the colonization of the invader and controlling the intestinal $\mathrm{pH}$ through the release of lactic and acetic acid (9). On the basis of numerous characteristics of many strains of LAB, particularly from the genera Lactobacillus and Bifidobacterium (10), the most recommended probiotics are $L$. plantarum, L. acidophilus, L. casei, Bifidobacterium bifidum, and Streptococcus lactis (11).

The majority of food for human consumption generated by LAB inoculants has been documented uropathogens growth inhibition zone (GIZ) for the fermentation of vegetables because vegetables are a good source of fermentable carbohydrates (12). Probiotics have been considered as biosafe and their easy application could be another inexpensive substitute to antibiotics, since many pathogenic microorganisms are now becoming resistant to them.

\section{Objectives}

To overcome the increasing incidence of bacterial infections in humans along with the growing rate of antibiotic resistance against commercially available antibiotics, the need of time is to develop biotherapeutic agents to control microbial pathogens. In this regard, the present study was carried out to isolate LAB capable of exerting antimicrobial agents against some multidrug-resistant uropathogens.

\section{Materials and Methods}

\subsection{Specimen Collection and Isolation of Lactic Acid Bacteria}

Rotten fruits (cucumber, wine, and strawberry) and vegetables (tomato, cauliflower, and eggplant) were collected from eight different markets of Sargodha, Pakistan. Ten grams of a given fruit/vegetable sample was homogenized in $10 \mathrm{~mL}$ of sterile distilled water by vortexing and transferred to $90 \mathrm{~mL}$ of a sterile $2.0 \%$ tri-sodium citrate solution in a sterile conical flask and mixed well. The decimal dilutions of the homogenates were prepared in a $0.85 \%$ sterile saline solution and plated on MRS agar media (Lab M, United Kingdom) (13). The plates were incubated at $37^{\circ} \mathrm{C}$ for 48 hours in anaerobic conditions. Isolated colonies were then picked from each plate and transferred to the MRS broth. The growth was processed for pure culturing, and the morphological characteristics of well-separated colonies in the MRS agar medium were recorded. The pure cultures were maintained in the MRS broth at $4^{\circ} \mathrm{C}$. All the cultures were sub cultured at 15 day intervals.

\subsection{Morphological, Physiochemical, and Biochemi- cal Characterization of Lactic Acid Bacteria Isolates}

The characteristics of Lactobacillus spp. presented in Bergeys' manual of Determinative Bacteriology (14) were determined for the isolates in this study. Accordingly, a 48 hours old growth culture of each isolate was processed for Gram straining, growth in $7.5 \% \mathrm{NaCl}$, production of catalase reaction and cytochrome oxidase activity, growth at $10^{\circ} \mathrm{C}$ and $45^{\circ} \mathrm{C}$, and lactic acid production (1). The biochemical and sugar fermentation tests were performed using the API 50CH strep system (Biomerieux France) according to the users' instructions manual. The physical growth conditions of the LAB isolates were optimized by measuring their growth at $\mathrm{pH} 4,5$, and 6 , and at $15^{\circ} \mathrm{C}, 37^{\circ} \mathrm{C}$, and $45^{\circ} \mathrm{C}$, with and without agitation, including $1 \%, 3 \%$, and $5 \%$ of inoculums. The isolates tentatively identified as $\mathrm{LAB}$ were stored at $20^{\circ} \mathrm{C}$ in the MRS broth using $50 \%(\mathrm{~W} / \mathrm{V})$ glycerol.

\subsection{Genetic Identification of Isolates}

\subsubsection{Identification through $16 S$ rRNA Gene Sequencing}

A given LAB isolate was grown at $37^{\circ} \mathrm{C}$ in the MRS broth for 24 hours, and the cells were then harvested by centrifugation for 20 minutes at $5,000 \mathrm{x} \mathrm{g}$ and $4^{\circ} \mathrm{C}$. The thawed pellet was re-suspended in $500 \mu \mathrm{L}$ of buffer (TE, $10 \mathrm{mmol} / \mathrm{L}$ Tris $\mathrm{HCl}$ and $1 \mathrm{mmol} / \mathrm{L}$ EDTA) and used for the extraction of DNA by phenol: chloroform method according to (15). DNA purification was carried out as described by (16). The purified DNA was used for the amplification of the 16S rRNA gene of the given isolates. Polymerase chain reaction (PCR) mixture comprised $2 \mu \mathrm{M}$ of each of Forward (5-AGAGTTTGATCCTGGCTCAG-3) and Reverse universal primers (5-ACGGHTACCTTGTTACGACTT-3), 2 $\mathrm{mM}$ of dNTP, $1 \mathrm{U}$ of Taq DNA polymerase, $1 \mathrm{X}$ PCR buffer, and 50 ng of template DNA in $25 \mu \mathrm{L}$ reaction volume with $1.5 \mathrm{mM}$ of $\mathrm{MgCl}_{2}$. The PCR conditions were: $94^{\circ} \mathrm{C}$ for $3 \mathrm{~min}$; followed by 30 cycles each of $94^{\circ} \mathrm{C} 30$ seconds, $55^{\circ} \mathrm{C} 3 \mathrm{sec}$ onds, $72^{\circ} \mathrm{C} 30$ seconds, and finally $72^{\circ} \mathrm{C}$ for 5 minutes. The PCR products were purified using QIAquick PCR Purification Kit/250 (Qiagen GmbH, Hilden, Germany) and were sequenced using the Eurofins MWG Operon sequencing 
service (USA). The sequences were aligned in the national center for biotechnology information (NCBI) database using the standard nucleotide-nucleotide homology search BLAST (the basic local alignment search tool) (http:/ www.ncbi.nlm.nih.gov/BLAST). Based on the percentage similarities, $3 \%$ of the isolates were identified as L. plantarum. The sequences of these isolates were deposited on GenBank, and accession numbers JF912378, JF912380, and JF912379 were obtained, respectively.

\subsection{Dissolution of Calcium Carbonate}

The MRS agar supplemented with $2 \% \mathrm{CaCO}_{3}$ was autoclaved routinely and poured into Petri plates and incubated overnight to check sterility. Discs of $3 \mathrm{~mm}$ diameter prepared from Whatman filter paper No.1 were autoclaved and kept in sterile conditions. Then, $50-100 \mu \mathrm{L}$ of a fresh 48-h-old culture of a given isolate was dispensed per disc by using sterile micropipettes. The loaded discs were left for drying in aseptic conditions and then pressed onto the prepared plates. The plates were incubated at $37^{\circ} \mathrm{C}$ for 24 hours. After incubation, the zones of $\mathrm{CaCO}_{3}$ dissolution were measured in millimeter (17).

\subsection{Antibiotic Susceptibility Assay}

The susceptibility to antibiotics of 7 uropathogens was determined by the diffusion of antibiotic disks (Oxoid) on diagnostic Sensitivity Test Agar (Oxoid), previously seeded with approximately $1 \times 10^{5} \mathrm{CFU} / \mathrm{mL}$ of each uropathogen. Five test uropathogens, viz. Candida albicans, Klebsiella pneumoniae, Pseudomonas aeruginosa, E. coli, and Enterococcus fecalis, were obtained from Children Hospital, Lahore, Pakistan, and two indicator strains, namely Escherichia coli DPC EC101 and Staphylococcus aureus DPC 6867, belonged to the culture collection of Teagasc food research centre, Moorepark, Fermoy, Co. Cork, Ireland.

The tested antibiotics and their minimal inhibitory concentration (MIC) ranges are given in Table 1. The growth inhibition zone (GIZ) diameters after overnight incubation of the plates at $37^{\circ} \mathrm{C}$ were measured as recommended by the clinical and laboratory standards institute (CLSI) (18). The MICs were determined for the Gram-negative and Gram-positive uropathogens via a broth microdilution test, while the Lactobacillus strains were tested by the VetMIC Assay.

As regards the VetMIC Assay, after overnight incubation, the agar cultures were checked for purity. For inoculum preparation, individual colonies were suspended in a sterile glass or plastic culture tube containing 2 to $5 \mathrm{~mL}$ of sterile saline (i.e. $0.85 \% \mathrm{NaCl}$ solution) until a density corresponding to a McFarland (McF) standard of 1 or a spectrophotometric equivalent $\left(3 \times 10^{8} \mathrm{CFU} / \mathrm{mL}\right)$ was obtained. The inoculated saline suspension was diluted 1:1,000 (for the inoculation of VetMIC plates) in the appropriate test medium to obtain a final concentration of $3 \times 10^{8} \mathrm{CFU} / \mathrm{mL}$, respectively, as recommended previously (19). The VetMIC (national veterinary institute, Uppsala, Sweden [http:// www.sva.se/en/Target-navigation/Services-Products/Vet$\mathrm{MIC} /]$ ) is a commercially available microtiter-based system comprising dried antimicrobials in serial twofold dilutions that can be stored for 2 years at room temperature.

Table 1. Tested Antibiotics and Their Minimal Inhibitory Concentration (MIC) Concentrations

\begin{tabular}{|c|c|c|c|c|}
\hline No. & Antibiotic & Class & Concentration & MIC ranges, $\mu \mathrm{g} / \mathrm{mL}^{\mathrm{a}}$ \\
\hline 1 & Gentamicin $^{\mathrm{b}}$ & Aminoglycoside & 10 & $0.5-256$ \\
\hline 2 & Kanamycin $^{\mathrm{b}}$ & Aminoglycoside & 30 & $2-1024$ \\
\hline 3 & Streptomycin ${ }^{\mathrm{b}}$ & Aminoglycoside & 10 & $0.5-256$ \\
\hline 4 & Neomycin ${ }^{\mathrm{b}}$ & Aminoglycoside & 15 & $0.5-256$ \\
\hline 5 & Tetracycline $^{\mathrm{b}}$ & Tetracycline & 30 & $0.125-64$ \\
\hline 6 & Ciprofloxacin ${ }^{\mathrm{b}}$ & Fluoroquinolone & 5 & $0.25-128$ \\
\hline 7 & Clindamycin ${ }^{\mathrm{b}}$ & Lincosamide & 2 & $0.032-16$ \\
\hline 8 & Chloramphenicol $^{\text {b }}$ & Chloramphenicol & 30 & $0.125-64$ \\
\hline 9 & Ampicillin ${ }^{\mathrm{b}}$ & $\beta$-Lactam & 10 & $0.032-16$ \\
\hline 10 & Penicillin ${ }^{\mathrm{C}}$ & $\beta$-Lactam & 10 & $0.032-16$ \\
\hline 11 & Erythromycin ${ }^{\mathrm{b}}$ & Macrolide & 15 & $0.016-8$ \\
\hline 12 & Vancomycin ${ }^{\mathrm{b}}$ & Glycopeptide & 30 & $0.25-128$ \\
\hline 13 & Virginiamycin ${ }^{\mathrm{b}}$ & Streptogramin & 10 & $0.016-8$ \\
\hline 14 & Linezolid $^{\mathrm{b}}$ & Oxazolidinone & 30 & $0.032-16$ \\
\hline 15 & Trimethoprim ${ }^{\mathrm{b}}$ & Dihydrofolate reductase inhibitor & 10 & $0.125-64$ \\
\hline 16 & Rifampicin ${ }^{\mathrm{b}}$ & Rifamycin & 5 & $0.125-64$ \\
\hline
\end{tabular}

\footnotetext{
${ }^{\mathrm{a}}$ Concentration range of the antibiotics according to the International Standard (ISO 10932:2010).

balues' unit is $\mu \mathrm{g}$.

'Values' unit is IU.
} 
One hundred microliters of the $3 \times 10^{8} \mathrm{CFU} / \mathrm{mL}$ inoculum was added to each well (yielding $3 \times 10^{4} \mathrm{CFU} /$ well) in columns 1 to 6 (strain 1 ) or 7 to 12 (strain 2 ) of individual VetMIC ${ }^{\mathrm{TM}}$ Lact-1 and VetMIC ${ }^{\mathrm{TM}}$ Lact-2 (Art no.395114) plates within 30 minutes after the preparation of the standardized inoculum. According to the VetMIC manufacturer, no additional homogenization step was required because the antimicrobial compound in each well dissolves easily in the test medium and diffuses to achieve equilibrium throughout the well. The microplates were incubated at $37^{\circ} \mathrm{C}$ using (anaerobic jars with "Anaerocult A" gas packs; Merck, Darmstadt, Germany) and the plates were piled with a lid between every two plates to generate a homogeneous environment throughout the jar.

Depending on whether the tests were performed at $37^{\circ} \mathrm{C}$, L. plantarum ATCC 14917 T (LMG 6907T) and L. paracasei ATCC 334, respectively, were included as a control strain during each susceptibility assay. As positive and negative controls, a standardized inoculum and un-inoculated test medium, respectively, were added to the wells without an antimicrobial compound. The last row in each plate was used as a sterility control and was inoculated with pure LSM broth. After $48 \mathrm{~h}$ of incubation, growth in the VetMIC ${ }^{\mathrm{TM}}$ Lact-1 and VetMIC ${ }^{\mathrm{TM}}$ Lact-2 systems was evaluated visually by comparing the pellet at the bottom of a well with the positive and negative controls. Any series of wells in which discontinuity in growth was observed were discarded. Irrespective of the bactericidal or bacteriostatic mechanism of the tested agent, the MIC was defined as the lowest antimicrobial concentration for which at least $80 \%$ visual reduction in growth was reported.

\subsection{In vitro Antimicrobial Activity of Lactic Acid Bacteria}

\subsubsection{Production of Bacteriocin-Like Inhibitory Sub- stances by Lactic Acid Bacteria Strains}

The antimicrobial activity was performed by selecting the LAB strains that showed clear zones of inhibition against uropathogen. A well-isolated colony of each LAB strain was selected from the MRS agar plate, and grown in the MRS broth overnight at $37^{\circ} \mathrm{C}$ to test the production of BLIS. The culture was centrifuged at $6,000 \times \mathrm{g}$ for $15 \mathrm{~min}$ utes at $4^{\circ} \mathrm{C}$, and the supernatant was neutralized to $\mathrm{pH} 7$ with $1 \mathrm{M}$ of $\mathrm{NaOH}$ and filter sterilized through $0.45 \mu \mathrm{m}$ (Sartorius Millipore filters) pore-size filters. The agar-well diffusion assay was used to determine the antimicrobial activity of the cell-free supernatant. All the studied test microorganisms (uropathogens) were grown in Brain Heart Infusion (BHI) broth, and then an overnight grown culture was seeded (1\%) into molten BHI agar plates. Six wells, each of $2 \mathrm{~mm}$ diameter and $3 \mathrm{~mm}$ depth, were then made in a required solidified medium. For a given plate, each well was dispensed with $50 \mu \mathrm{L}$ of a cell-free filtrate of a given $\mathrm{LAB}$ isolate. The supernatant was allowed to dry for 1 hour inside the wells at room temperature and incubated overnight in the anaerobic chamber at $37^{\circ} \mathrm{C}$. Thereafter, an extra plate 1 was poured to ensure an even lawn of cells in the absence of any antimicrobial agent. All the agar plates were examined for a zone of inhibition following overnight incubation. The activity was also tested against selected indicator strains (Staphylococcus aureus DPC 6867 and E. coli EC101) (20).

\section{Results}

In total, $54 \mathrm{LAB}$ strains were isolated from spoiled fruits and vegetables from 8 different food markets of Sargodha, Pakistan. The dominant colony types were continuously streaked on selective growth media (MRS), and 11 isolates were tentatively identified as Lactobacillus spp. on the basis of their morphological, biochemical, and metabolic characteristics (Table 3), as well as with API 50 $\mathrm{CH}$ fermentation strips (Table 4). All the strains belonged to the genus Lactobacillus and were assigned codes as follows: L. acidophilus (AS-1); L. paracasei (AS-2); L. delbrueckii (AS-3); L. plantarum (AS-4); L. helveticus (AS-5); L. brevis (AS6); L. salivarius (AS-7); L. fermentum (AS-8); L. rhamnosus (AS9); L. plantarum (AS-13); and L. plantarum (AS-14). The latter strain had the highest abundance, and complete identification at species level was done by partial sequencing of the 16s rRNA gene. The designation codes JF912378, JF912379, and JF912380 were given to L. plantarum AS-4, AS13, and AS-14, respectively.

The colony morphology on the MRS of all the Lactobacillus strains was shown to be off-white, round, convex, smooth, and opaque with a size of $10 \mu \mathrm{m}$ after 48 hours growth at $37^{\circ} \mathrm{C}$, while the color of the strains turned to yellow and they became rough upon longer periods of incubation. All the isolates had round colonies, were Gram-positive coccobacilli, facultative anaerobes and appeared negative for endospore, capsule, motility, catalase, oxidase, and $\mathrm{CaCO}_{3}$ utilization test. The evolution of $\mathrm{CO}_{2}$ was assessed by the Durham tube method, and the test was considered negative when no gas appeared in the Durham tube following fermentation in the MRS medium. The LAB strains were capable of fermenting sugars as ribose, sorbitol, mannose, lactose, raffinose, mannitol, and salicin. However, L. brevis was unable to ferment raffinose, while L. acidophilus and L. salivarius lacked the ability to ferment ribose (Table 3). According to the results of the carbohydrate utilization test using API 50CH strips (API LAB 50 CHL software) for the species identification, 3 species of the isolated lactobacilli showed differences in their sugar fermentation profiles and they were identified as L. plantarum (Table 3). Furthermore, it was shown that lactic acid production varied among the strains, where L. paracasei, L. rhamnosus, and L. plantarum produced higher concentrations of lactic acid (over $21 \mathrm{mg} / \mathrm{mL}$ ) compared to the other Lactobacillus isolates (Table 2 ). 
Manzoor A et al.

\begin{tabular}{|c|c|c|c|c|c|c|c|c|c|c|c|}
\hline LAB Identified & $\begin{array}{c}\text { L. } \\
\text { acidophilic }\end{array}$ & $\begin{array}{c}\text { L. } \\
\text { paracasei }\end{array}$ & $\begin{array}{c}\text { L. } \\
\text { delbrueckii }\end{array}$ & $\begin{array}{c}\text { L. } \\
\text { helveticus }\end{array}$ & L. brevis & $\begin{array}{c}\text { L. } \\
\text { salivarius }\end{array}$ & $\begin{array}{c}\text { L. } \\
\text { fermentum }\end{array}$ & $\begin{array}{l}\text { L. } \\
\text { rhamnosus }\end{array}$ & $\begin{array}{c}\text { L. } \\
\text { slantarum }\end{array}$ & $\begin{array}{c}\text { L. } \\
\text { plantarum }\end{array}$ & $\begin{array}{c}\text { L. } \\
\text { plantarum }\end{array}$ \\
\hline Strain Codes & AS-1 & AS-2 & AS-3 & AS-5 & AS-6 & AS-7 & AS-8 & AS-9 & JF912378 & JF912379 & JF912380 \\
\hline Growth at $15^{\circ} \mathrm{C}$ & - & - & - & - & - & - & - & - & - & - & - \\
\hline Growth at $37^{\circ} \mathrm{C}$ & + & + & + & + & + & + & + & + & + & + & + \\
\hline Growth at $45^{\circ} \mathrm{C}$ & + & - & + & + & + & - & + & - & + & + & + \\
\hline Motility & - & - & - & - & - & - & - & - & - & - & - \\
\hline Catalase & - & - & - & - & - & - & - & - & - & - & - \\
\hline $\begin{array}{l}\mathrm{CO}_{2} \text { production } \\
\text { from glucose }\end{array}$ & - & - & - & - & + & - & + & - & - & - & - \\
\hline $\begin{array}{l}\text { Lactic acid } \\
\text { production, mg/mL }\end{array}$ & $15.98 \pm 2.4$ & $22.87 \pm 1.45$ & $20.65 \pm 0.78$ & $18.77 \pm 0.63$ & $\begin{array}{c}17.67 \pm \\
1.59\end{array}$ & $16.99 \pm 1.37$ & $19.22 \pm 0.99$ & $21.75 \pm 0.58$ & $21.23 \pm 0.49$ & $\begin{array}{c}20.66 \pm \\
0.74\end{array}$ & $22.18 \pm 1.28$ \\
\hline $\begin{array}{l}\mathrm{CaCO}_{3} \text { Dissolution } \\
\text { zone, } \mathrm{mm}\end{array}$ & $15.0 \pm 1.4$ & $15.0 \pm 1.13$ & $18.0 \pm 1.35$ & $15.0 \pm 2.41$ & $15.0 \pm 1.24$ & $12.0 \pm 2.52$ & $19.0 \pm 1.17$ & $14.0 \pm 1.34$ & $13.0 \pm 1.5$ & $21.0 \pm 2.40$ & $16.0 \pm 1.8$ \\
\hline Gram staining & + & + & + & + & + & + & + & + & + & + & + \\
\hline
\end{tabular}

The growth pattern of all the strains in the MRS agar with three $\mathrm{pH}$ levels ( $\mathrm{pH} 4.0,5.0$, and 6.0) is depicted in Figure $1 \mathrm{~A}$, showing that the best growth was obtained at $\mathrm{pH}$ 6.0, while $\mathrm{pH} 4.0$ significantly reduced the growth. The concentration of inoculums was found to be the best at $5 \%$ for most of the Lactobacillus isolates, except L. acidophilus AS-1 and L. paracasei AS-2, which showed the best growth when inoculated at 3\%. Interestingly, L. brevis AS-6 had a similar growth at all inoculum concentrations. The best growth of all the isolates was at $37^{\circ} \mathrm{C}$, while they grew slower at $45^{\circ} \mathrm{C}$. The growth of all lactobacilli was significantly reduced at $15^{\circ} \mathrm{C}$, where almost no growth was observed (Figure 1C).

The results of the antibiotic susceptibility of the isolated Lactobacilli are shown in Table 5. The MIC distribution of the tested antibiotics is summarized with regard to the 11 Lactobacillus strains. In the EFSA guidelines, microbiological breakpoints for $L$. brevis have not been discussed individually. For this reason, the respective MICs were interpreted by using the breakpoints given for the general Gram-positive Lactobacillus bacteria. According to the results, all the lactobacilli were susceptible to 15 out of the 16 applied antibiotics, except L. acidophilus AS- 1 and L. plantarum JF912378, which were susceptible to 14 antibiotics. Apart from vancomycin, $L$. acidophilus AS-1 and $L$. plantarum JF912378 displayed resistance to trimethoprim and streptomycin, respectively, while the other isolates were resistant only against vancomycin.

The susceptibility pattern of the uropathogen microorganisms to 16 antibiotics (Table 4) was observed according to their microbiological breakpoints as recommended by the FEEDAP document on the assessment of bacterial products used as additives in food products in relation to antibiotic resistance (EFSA 2012). The results of the antibiotic susceptibility test revealed that all the uropathogens showed multiple antibiotic resistance, which varied from 3 to 5 antibiotics, depending on the strain. All the tested uropathogens, including the 2 reference strains Escherichia coli DPC EC101 and Staphylococcus aureus DPC 6867, showed a high rate of resistance to ciprofloxacin, erythromycin, and vancomycin. The tested pathogens C. albicans, P. aeruginosa and K. pneumonia were also resistant to kanamycin, while the indicator strains E. coli DPC EC101 and S. aureus DPC 6867 displayed resistance to trimethoprim. All the uropathogens showed susceptibility to gentamicin, streptomycin, neomycin, tetracycline, clindamycin, ampicillin, penicillin, virginiamycin, linezolid, and rifampicin. On the other hand, E. fecalis and E. coli exhibited resistance to chloramphenicol, while the 2 reference strains were clearly susceptible to this antibiotic (Table 4).

Importantly, the identified lactobacilli showed a broad spectrum of antimicrobial activity against all the 5 tested uropathogens, while the antagonistic activity against the indicator strains was selective. The isolated bacterium $L$. acidophilus AS-1 expressed a GIZ of $19 \mathrm{~mm}$ against E. coli, while L. plantarum strains JF912378, JF912379, and JF912380 showed a higher GIZ of 23, 24, and $22 \mathrm{~mm}$, respectively. Moreover, all the L. plantarum isolates, including L. salivarius AS-7 and L. fermentum AS-8, had even a higher GIZ against E. faecalis (26-28 mm), while the rest of the isolated lactobacilli had a GIZ below $20 \mathrm{~mm}$. However, all the isolated strains showed an inhibitory effect against $C$. albicans, P. aeruginosa, and K. pneumoniae with a GIZ up to 14,13 , and $15 \mathrm{~mm}$, correspondingly.

The indicator strain Staphylococcus aureus DPC 6867 showed resistance to all the Lactobacillus isolates, while Escherichia coli DPC EC101 was resistant only to L. salivarius AS-7. However, this reference strain showed higher susceptibility to all the L. plantarum isolates (GIZ $>12 \mathrm{~mm}$ ) and moderate susceptibility to the other Lactobacilli isolated $(\mathrm{GIZ}<9 \mathrm{~mm})$. 
Manzoor A et al.

\begin{tabular}{|c|c|c|c|c|c|c|c|c|c|c|c|}
\hline \multirow[t]{2}{*}{ Sugar/Sugar Alcohol } & \multicolumn{11}{|c|}{ Lactobacillus Isolates } \\
\hline & AS-1 & AS-2 & AS-3 & AS-5 & AS-6 & AS-7 & AS-8 & AS-9 & JF 912378 & JF 912379 & JF 912380 \\
\hline Glycerol & - & + & + & - & - & - & - & + & + & - & - \\
\hline Erythritol & - & - & - & - & - & - & - & - & - & - & - \\
\hline D-Arabinose & - & - & - & - & - & - & - & - & - & - & - \\
\hline L-Arabinose & - & - & + & + & + & - & + & - & + & - & + \\
\hline D-Ribose & - & + & + & + & + & - & + & + & + & + & + \\
\hline L-Xylose & - & - & - & + & + & - & + & - & - & + & + \\
\hline D-Xylose & - & - & - & + & - & - & + & + & - & - & - \\
\hline D-Adonitol & - & - & - & - & - & - & + & + & - & - & - \\
\hline Methyl $\beta$-D-xylopyranoside & - & - & - & - & - & - & + & + & - & - & - \\
\hline D-Galactose & - & + & + & + & - & + & + & + & + & - & - \\
\hline D-Glucose & + & + & + & + & + & + & + & + & + & + & + \\
\hline D-Fructose & + & + & + & + & - & + & + & + & + & + & + \\
\hline D-Mannose & + & + & + & + & - & + & - & + & + & + & + \\
\hline L-Sorbose & - & - & - & - & - & - & - & + & - & + & + \\
\hline L-Rhamnose & - & - & - & - & - & + & - & - & - & - & + \\
\hline Dulcitol & - & - & - & - & - & - & - & - & - & + & - \\
\hline Inositol & - & - & - & - & - & - & - & - & - & - & - \\
\hline D-Mannitol & - & + & + & - & - & + & - & + & + & + & + \\
\hline D-Sorbitol & - & + & + & - & - & + & - & + & + & + & - \\
\hline Methyl $\alpha$-D-mannopyranoside & i.c. & - & - & + & - & - & - & + & + & + & + \\
\hline Methyl $\alpha$-D-glucopyranoside & i.c. & - & + & - & - & - & i.c. & i.c. & + & + & + \\
\hline N-Acetylglucosamine & - & + & + & - & - & + & i.c. & i.c. & + & + & - \\
\hline Amygdalin & - & + & + & + & - & - & - & - & + & + & - \\
\hline Arbutin & - & + & + & + & - & - & - & - & + & + & + \\
\hline Esculin ferric citrate & - & + & + & + & - & - & - & - & + & + & + \\
\hline Salicin & - & + & + & + & - & - & - & - & + & + & + \\
\hline D-Csellobiose & - & + & - & - & - & - & - & + & + & + & - \\
\hline D-Maltose & - & + & + & + & - & + & - & + & + & + & + \\
\hline D-Lactose & + & + & + & + & + & + & + & + & + & + & + \\
\hline D-Melibiose & - & - & - & + & - & + & - & - & + & + & + \\
\hline D-Sucrose & + & + & + & + & - & + & + & + & + & + & + \\
\hline D-Trehalose & - & + & + & + & - & + & - & + & + & + & + \\
\hline Inuline & - & - & + & + & - & - & - & - & + & + & + \\
\hline D-Melezitose & - & + & - & - & - & - & - & - & - & i.c. & + \\
\hline D-Raffinose & + & + & + & + & - & + & + & + & + & + & + \\
\hline Starch & - & - & + & - & - & - & - & + & - & + & + \\
\hline Glycogen & - & - & - & + & - & - & - & - & - & + & - \\
\hline Xylitol & - & - & - & + & - & - & - & - & - & + & - \\
\hline Gentiobiose & - & + & + & + & - & - & - & - & + & + & - \\
\hline D-Turanose & - & - & + & + & - & - & - & - & + & - & - \\
\hline D-Xylose & - & - & - & - & - & - & - & + & - & + & + \\
\hline D-Tagatose & - & + & - & - & - & - & - & - & - & - & - \\
\hline D-Fucose & - & - & - & - & - & - & - & - & - & - & - \\
\hline L-Fucose & - & - & - & - & - & - & - & - & - & - & - \\
\hline D-Arabitol & - & - & - & - & - & - & - & - & - & - & - \\
\hline L-Arabitol & - & - & - & + & - & - & - & + & - & + & - \\
\hline Potassium gluconate & i.c. & - & + & + & - & - & i.c. & i.c. & + & + & - \\
\hline Potassium-2-ketogluconate & - & - & - & - & - & - & - & - & - & - & + \\
\hline Potassium-5-ketogluconate & - & - & - & + & + & - & - & + & - & - & - \\
\hline
\end{tabular}

\footnotetext{
a“+”"indicates color change; “- " indicates no change in color; "i.c.” indicates intermediate color.
} 
Manzoor A et al.

Table 4. Minimum Inhibitory Concentration (MIC) Distribution of Sixteen Antibiotics for Five Test Uropathogens and Two Indicator Microorganisms

\begin{tabular}{|c|c|c|c|c|c|c|c|c|c|c|c|c|c|c|c|}
\hline \multirow[t]{2}{*}{ Antibiotics } & \multicolumn{14}{|c|}{ Minimum Inhibitory Concentration (MIC) Values ${ }^{a}$} & \multirow{2}{*}{$\begin{array}{c}\text { MIC } \\
\text { Breakpoints a,b }\end{array}$} \\
\hline & 0.25 & 0.5 & 1 & 2 & 4 & 8 & 16 & 32 & 64 & 128 & 256 & 512 & 1024 & 2048 & \\
\hline \multicolumn{16}{|c|}{ Tested uropathogens and indicator strains ${ }^{C}$} \\
\hline Gentamicin & & & & & & f, g & $\mathrm{d}, \mathrm{e}$ & $\mathrm{a}, \mathrm{b}, \mathrm{c}$ & & & & & & & 32 (b,e,f, g:16) \\
\hline Kanamycin & & & & & & & & & & & $f, g$ & & $\mathrm{~d}, e$ & $a, b, c$ & d: 512;e, f: 8; g: 64 \\
\hline Streptomycin & & & & & & & & $\mathrm{g}$ & $d, f$ & $\mathrm{a}, \mathrm{b}, \mathrm{c}, \mathrm{e}$ & & & & & 128 \\
\hline Neomycin & & & & & & $f, g$ & $a, b, c$ & $\mathrm{~d}, \mathrm{e}$ & & & & & & & 32 \\
\hline Tetracycline & & & $\mathrm{f}, \mathrm{g}$ & $\mathrm{a}, \mathrm{b}, \mathrm{c}, \mathrm{d}, \mathrm{e}$ & & & & & & & & & & & 16 \\
\hline Ciprofloxacin & & & & & & $d, e, f, g$ & $a, b, c$ & & & & & & & & 4 \\
\hline Clindamycin & & & & $\mathrm{F}$ & $\mathrm{d}, \mathrm{e}$ & g & $a, b, c$ & & & & & & & & N.A. $(g: 1)$ \\
\hline Chloramphenicol & & & & & & $\mathrm{f}, \mathrm{g}$ & $\mathrm{a}, \mathrm{b}, \mathrm{c}$ & d, e & & & & & & & $16(d, e, f: 32)$ \\
\hline Ampicillin & & g & $a, b, c, f$ & d,e & & & & & & & & & & & 32 (d:16; g: 0.5$)$ \\
\hline Penicillin & g & & $\mathrm{f}$ & $a, b, c, d, e$ & & & & & & & & & & & $16(\mathrm{~g}: 0.25)$ \\
\hline Erythromycin & & & & & & $b, c, \mathrm{~d}, \mathrm{e}, f, g$ & & & & & & & & & $4(\mathrm{~d}: 8)$ \\
\hline Vancomycin & & & & & & $b, c, \mathrm{~d}, e, f, \mathrm{~g}$ & & & & & & & & & $4(\mathrm{~d}: 12 ; \mathrm{g}: 16)$ \\
\hline Virginiamycin & & & & f,g & $a, b, c$ & $\mathrm{~d}, \mathrm{f}$ & & & & & & & & & N.A. \\
\hline Linezolid & & & & $a, b, c$ & $\mathrm{f}, \mathrm{g}$ & $\mathrm{d}, \mathrm{e}$ & & & & & & & & & N.A. (d: 8) \\
\hline Trimethoprim & & & & $f, g$ & $a, b, c$ & $d, \mathrm{e}$ & & & & & & & & & 2 (b: 8; e, f, g:16) \\
\hline Rifampicin & & & & $\mathrm{f}, \mathrm{g}$ & $\mathrm{a}, \mathrm{b}, \mathrm{c}$ & $d, \mathrm{e}$ & & & & & & & & & N.A. (d, g: 4) \\
\hline
\end{tabular}

a Values' unit is $\mu \mathrm{g} / \mathrm{mL}$.

${ }^{\mathrm{MIC}}$ breakpoints according to the CLSI (2007) and EFSA (2008, 2012).

$\mathrm{c}_{\mathrm{a}}$, C. albicans; b, P. aeruginosa, c, K. pneumoniae, d, E. faecalis, e, E. coli, f, E. coli EC101, g, S. aureus DPC 6867; N.A, not available; Strains with MICs higher than the MIC breakpoints are considered as resistant and indicated by the italic font.

Table 5. Minimum Inhibitory Concentration (MIC) Distribution of Sixteen Antibiotics for Eleven Lactobacillus Strains ${ }^{\mathrm{a}}$

\begin{tabular}{|c|c|c|c|c|c|c|c|c|c|c|c|c|c|c|c|c|}
\hline Antib & Gm & $\mathrm{Km}$ & Sm & Nm & Tc & $\mathbf{C i}$ & $\mathbf{C l}$ & $\mathbf{C m}$ & Am & Pc & Em & Va & Vi & Lz & Tm & $\mathbf{R i}$ \\
\hline $\begin{array}{l}\text { Dilution } \\
\text { Ranges, } \mu \mathrm{g} / \mathrm{mL}\end{array}$ & $\begin{array}{l}0.5- \\
256\end{array}$ & $1-256$ & $0.5-256$ & $0.5-256$ & $\begin{array}{l}0.125- \\
256\end{array}$ & $\begin{array}{l}0.25- \\
128.0\end{array}$ & $\begin{array}{c}0.032- \\
16.0\end{array}$ & $\begin{array}{c}0.125- \\
64.0\end{array}$ & $\begin{array}{c}0.032- \\
16.0\end{array}$ & $\begin{array}{c}0.032- \\
16.0\end{array}$ & $\begin{array}{c}0.016- \\
8.0\end{array}$ & $\begin{array}{l}0.25- \\
128.0\end{array}$ & $\begin{array}{c}0.016- \\
8.0\end{array}$ & $\begin{array}{c}0.032- \\
16.0\end{array}$ & $\begin{array}{c}0.125- \\
64.0\end{array}$ & $\begin{array}{l}0.25- \\
128.0\end{array}$ \\
\hline \multicolumn{17}{|c|}{ MICs readings of tested Lactobacillus strains ${ }^{b}$} \\
\hline $\begin{array}{l}\text { L. acidophilus } \\
\text { AS-1 }\end{array}$ & $4(16)$ & $8(16)$ & $16(16)$ & $2(16)$ & $2(4)$ & $32($ n.a) & $0.5(1)$ & $2(4)$ & $0.5(1)$ & $\begin{array}{r}\geq 16 \\
\text { (n.a) }\end{array}$ & $0.25(1)$ & $\geq 128(2)$ & $1(\mathrm{n} . \mathrm{a})$ & $2($ n.a) & $\begin{array}{l}\geq 128 \\
\text { (n.a) }\end{array}$ & 8 (n.a) \\
\hline L.paracasei AS-2 & $16(32)$ & $32(64)$ & $16(n \cdot r)$ & $16(32)$ & $1(4)$ & $16($ n.a) & $0.25(1)$ & $2(4)$ & $0.25(2)$ & $8($ n.a) & $0.12(1)$ & $\begin{array}{l}\geq 128 \\
\text { (n.r) }\end{array}$ & 2 (n.a) & 4 (n.a) & $0(n . a)$ & $8(\mathrm{n} . \mathrm{a})$ \\
\hline $\begin{array}{l}\text { L. delbr } \\
\text { AS-3 }\end{array}$ & $4(16)$ & $4(16)$ & $8(16)$ & $8(16)$ & $\begin{array}{l}0.5 \\
(4)\end{array}$ & $32(\mathrm{n} . \mathrm{a})$ & $0.5(1)$ & $1(4)$ & $0.5(1)$ & $4($ n.a) & $0.25(1)$ & $32(2)$ & 2 (n.a) & 4 (n.a) & 64 (n.a) & $16($ n.a) \\
\hline L. helveticus AS-5 & $4(16)$ & $8(16)$ & $8(16)$ & $4(16)$ & $2(4)$ & 32 (n.a) & $0.12(1)$ & $2(4)$ & $0.5(1)$ & 4 (n.a) & $0.06(1)$ & $32(2)$ & 2 (n.a) & 2 (n.a) & 16 (n.a) & $16(n . a)$ \\
\hline L. brevis AS-6 & $2(4)$ & $8(16)$ & $8(8)$ & $2(4)$ & $0.5(2)$ & 64 (n.a) & $\begin{array}{c}0.12 \\
(0.25)\end{array}$ & $2(2)$ & $0.25(1)$ & $4(\mathrm{n} . \mathrm{a})$ & $\begin{array}{l}0.06 \\
(0.5)\end{array}$ & $128(2)$ & 4 (n.a) & 4 (n.a) & 32 (n.a) & 4 (n.a) \\
\hline L. salivarius AS-7 & $4(16)$ & $32(64)$ & $32(64)$ & $2(16)$ & $4(8)$ & 64 (n.a) & $0.5(1)$ & $2(4)$ & $2(4)$ & 4 (n.a) & $0.25(1)$ & $\begin{array}{l}\geq 128 \\
\text { (n.r) }\end{array}$ & 2 (n.a) & 4 (n.a) & 64 (n.a) & $8(\mathrm{n} . \mathrm{a})$ \\
\hline $\begin{array}{l}\text { L.fermentum } \\
\text { AS-8 }\end{array}$ & $2(16)$ & $16(32)$ & $32(64)$ & $4(16)$ & $2(8)$ & $16(\mathrm{n} . \mathrm{a})$ & $0.5(1)$ & $1(4)$ & $0.5(1)$ & 0 (n.a) & $0.12(1)$ & $32(n . r)$ & 1 (n.a) & $16(n . a)$ & 32 (n.a) & $8($ n.a) \\
\hline $\begin{array}{l}\text { L. rhamnosus } \\
\text { AS-9 }\end{array}$ & $4(16)$ & $32(64)$ & $16(32)$ & $2(16)$ & $4(8)$ & 16 (n.a) & $0.5(1)$ & $1(4)$ & $2(4)$ & $0(\mathrm{n} . \mathrm{a})$ & $0.06(1)$ & 32 (n.r) & 1 (n.a) & $8(n . a)$ & 16 (n.a) & 8 (n.a) \\
\hline $\begin{array}{l}\text { L. plantarum JF } \\
912378\end{array}$ & $4(16)$ & $16(64)$ & $\begin{array}{l}\geq 256 \\
\text { (n.r) }\end{array}$ & $4(16)$ & $8(32)$ & 32 (n.a) & $0.25(1)$ & $2(4)$ & $0.25(2)$ & $4(\mathrm{n} . \mathrm{a})$ & $0.12(1)$ & $\begin{array}{l}\geq 128 \\
\text { (n.r) }\end{array}$ & 2 (n.a) & $16(n . a)$ & 64 (n.a) & $8($ n.a) \\
\hline $\begin{array}{l}\text { L. plantarum JF } \\
912379\end{array}$ & $4(16)$ & $32(64)$ & $\begin{array}{l}\geq 256 \\
\text { (n.r) }\end{array}$ & $4(16)$ & $8(32)$ & 32 (n.a) & $0.25(1)$ & $2(4)$ & $0.5(2)$ & $0(\mathrm{n} . \mathrm{a})$ & $0.12(1)$ & $\begin{array}{l}\geq 128 \\
\text { (n.r) }\end{array}$ & 2 (n.a) & $16(n . a)$ & 64 (n.a) & $8($ n.a) \\
\hline $\begin{array}{l}\text { L. plantarum JF } \\
912380\end{array}$ & $4(16)$ & $16(64)$ & $\begin{array}{l}\geq 256 \\
\text { (n.r) }\end{array}$ & $8(16)$ & $8(32)$ & 16 (n.a) & $0.25(1)$ & $2(4)$ & $0.25(2)$ & $0(\mathrm{n} . \mathrm{a})$ & $0.12(1)$ & $\begin{array}{l}\geq 128 \\
\text { (n.r) }\end{array}$ & 1 (n.a) & $16(\mathrm{n} . \mathrm{a})$ & 16 (n.a) & 8 (n.a) \\
\hline
\end{tabular}

a Abbreviations: Am: Ampicillin; Ci: Ciprofloxacin; Em: Erythromycin; Gm: Gentamycin; Cl: Clindamycin; Cm: Chloramphenicol; Km: Kanamycin; Lz: Linezolid; n.a., not available; Nm: Neomycin; Pc: Penicillin; Ri: Rifampicin; Sm: Streptomycin; Tc: Tetracycline; Tm:Trimethoprim; n.r., not required; Va: Vancomycin; Vi: Virginiamycin.

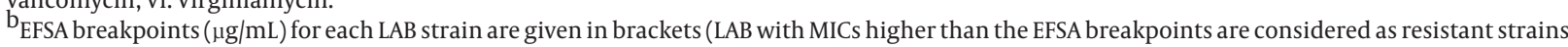
and indicated by the italic font). 
Manzoor A et al.

Table 6. Antimicrobial Effects of Lactobacillus Strains (Cell-Free Supernatant) against Uropathogens

Lactobacillus Strains $\quad$ Uropathogens Growth Inhibition Zone (GIZ) $)^{\mathrm{a}, \mathrm{b}} \quad$ Indicator Strains

C. albicans P.aeruginosa K. pneumoniae E.faecalis E. coli E. coli DPC EC101 S. aureus DPC 6867

\begin{tabular}{|c|c|c|c|c|c|c|c|}
\hline L. acidophilus AS-1 & ++ & ++ & ++ & ++ & ++ & + & $\mathrm{R}$ \\
\hline L. paracasei AS-2 & ++ & ++ & ++ & ++ & ++ & + & $\mathrm{R}$ \\
\hline L. delbrueckii AS-3 & ++ & ++ & ++ & ++ & ++ & + & $\mathrm{R}$ \\
\hline L. helveticus AS-5 & ++ & ++ & ++ & ++ & ++ & + & $\mathrm{R}$ \\
\hline L. brevis AS-6 & ++ & ++ & ++ & ++ & ++ & + & $\mathrm{R}$ \\
\hline L. salivarius AS-7 & ++ & ++ & ++ & +++ & ++ & $\mathrm{R}$ & $\mathrm{R}$ \\
\hline L. fermentum AS-8 & ++ & ++ & ++ & +++ & ++ & + & $\mathrm{R}$ \\
\hline L. rhamnosus AS-9 & ++ & ++ & ++ & ++ & ++ & + & $\mathrm{R}$ \\
\hline L. plantarum JF 912378 & ++ & ++ & ++ & +++ & +++ & ++ & $\mathrm{R}$ \\
\hline L. plantarumJF 912379 & ++ & ++ & ++ & +++ & +++ & ++ & $\mathrm{R}$ \\
\hline L. plantarum JF 912380 & ++ & ++ & ++ & +++ & +++ & ++ & $\mathrm{R}$ \\
\hline
\end{tabular}

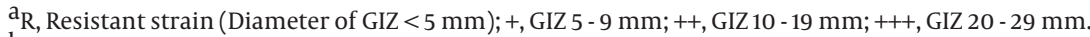

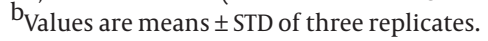

\section{Discussion}

The present study was carried out to isolate LAB with a new strategy for the treatment of UTI as an alternative to antibiotics by inhibiting uropathogens due to the production of proteinaceous compound BLIS. The potential practical application of bacteriocins in the preservation of food and in the prevention and treatment of bacterial infection has been previously investigated $(4,21,22)$. Out of 54 positive colonies screened from the MRS agar, only 11 were identified as LAB after characterization by cell morphological, physiological, and biochemical tests and through $16 \mathrm{~S}$ rRNA gene sequencing. Among the 11 confirmed cultures, the 3 identified isolates belonged to the same specie as L. plantarum. The rest of the isolates represented L. acidophilus, L. paracasei, L. salivarius, L. delbrueckii, L. casei, L. helveticus, L. brevis, L. fermentum, and $L$. rhamnosus. The only $\mathrm{LAB}$ species selected for nucleotide sequence submission to the NCBI was L. plantarum due to their highest response of inhibitory action against the uropathogens used in this study as compared to the other isolates. Mallesha et al. (22) reported 44 strains of bacteriocin-producing $\mathrm{LAB}$ from raw fermented foods, while the isolation of LAB from fresh fruits and vegetables and their biocontrol potential against phytopathogenic spoilage bacteria and fungi have also been studied by other authors (23).

Margolles et al. (24) identified L. paracasei and L. brevis and reported that these $2 \mathrm{LAB}$ species not only naturally associated with plant and animal environments but could be present as contaminant in meat, vegetables, and cereals owing to its use in traditional food fermentation. The API system showed good agreement with molecular identification for the above-mentioned LAB isolates with the previous studies of Boyd et al. (25). The main characteristic of lactobacilli is the fermentation of lactose, which lowers the $\mathrm{pH}$ as a result of acid formation. Lactic acid and other organic acids have an inhibitory effect on further bacterial growth (25). Thus, the growth of Lactobacilli was observed after 40 minutes of incubation at varying levels of $\mathrm{pH} 4.0,5.0$, and 6.0. All the isolates showed maximal growth at $\mathrm{pH} 6.0$, although their growth was also present at pH 5.0, but to a smaller extent. However, significantly reduced growth was detected after incubation at $\mathrm{pH} 4.0$ (Figure $1 \mathrm{~A}$ ).

Sarika et al. (26) studied the effect of different $\mathrm{pH}$ ranges ( $\mathrm{pH} 4,5,6$, and 7) on the growth of L. bulgaricus subsp. delbrueckii and observed that maximum growth was at $\mathrm{pH}$ 6. Moreover, the inoculum size, incubation temperature, and incubation time are important parameters to assess the antibiotic susceptibility among LAB (26). In this work, in order to achieve the maximum microbial population among the LAB strains, the influence of the inoculum size (1\%, 3\%, and 5\%), incubation time ( 24 hours, 48 hours, and 72 hours), and incubation temperature $\left(15^{\circ} \mathrm{C}, 37^{\circ} \mathrm{C}\right.$, and $45^{\circ} \mathrm{C}$ ) on bacterial growth was observed. The LAB strains (AS-4, AS-13, and AS-14) showed the best growth in 5\% inoculum (Figure $1 \mathrm{~B}$ ) during a 48 hours incubation time and at $37^{\circ} \mathrm{C}$ temperature (Figure $1 \mathrm{C}$ ). Similar results were also reported by Lim et al. (27). 

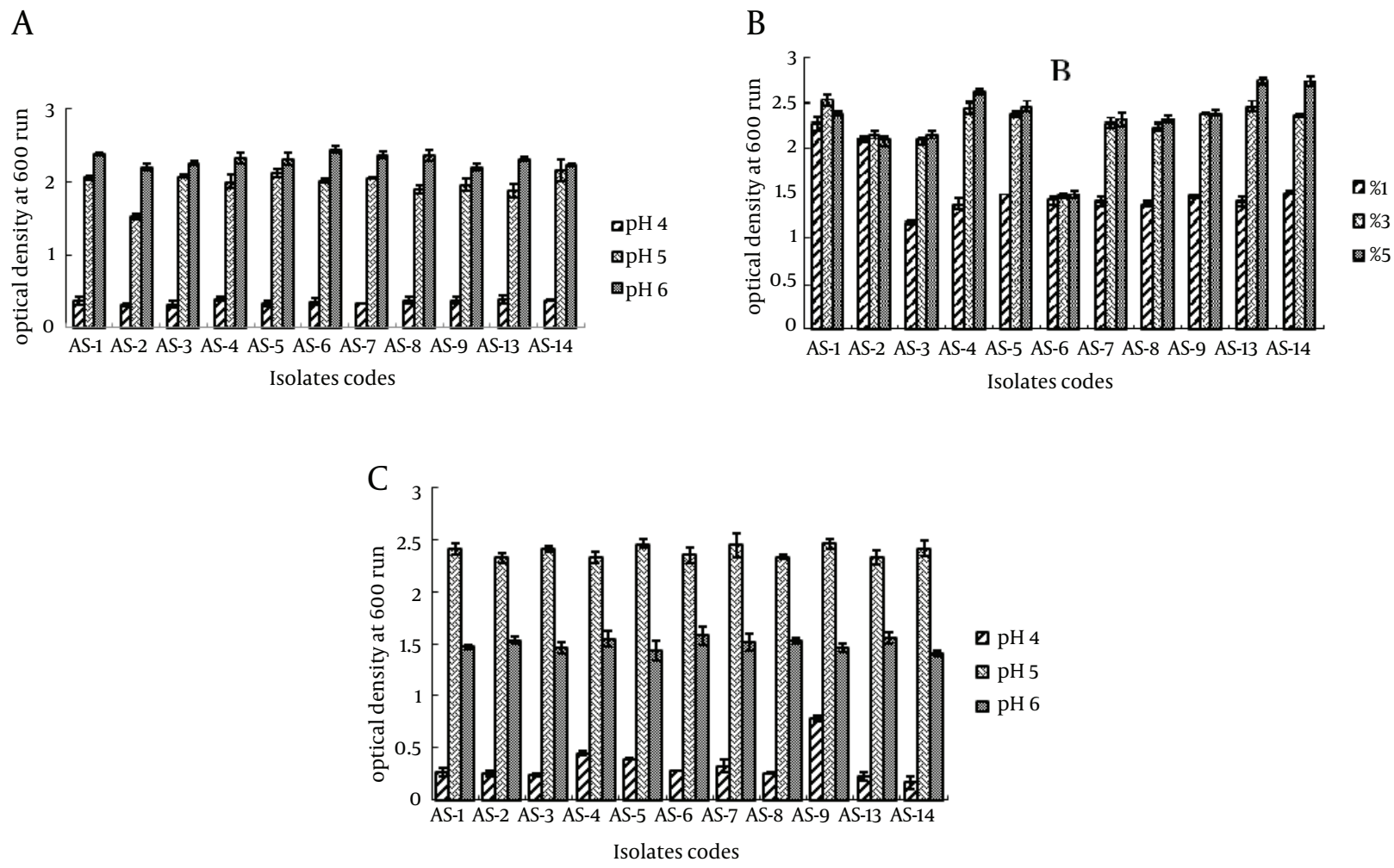

$\mathrm{A}$, at $37^{\circ} \mathrm{C}$, inoculums size; $\mathrm{B}$, and incubation temperature; C, for 48 hours.

In developing countries like Pakistan, an increasing medical problem is the antibiotic resistance of pathogenic bacteria, which raises the question of antibiotic resistance among desired probiotic strains. One of the common clinical problems in children is UTI, and clinicians have tried to eradicate the disease through the application of a wide array of treatment strategies. Nevertheless, there is a dearth of data on the treatment of UTI in children, whereas there is a great deal of information on the application of probiotics for the cure of UTI in female adults (27). The resistance of uropathogenic strains against standard antibiotics and susceptibility to isolated LAB strains were tested in the present study. In this study, C. albicans and E. coli were found predominant microorganisms responsible for UTI. This agrees with the findings of other researchers (26) who reported that the major catheter-associated UTI causing microorganism was E. coli, followed by Staphylococcus spp.

In this study, 3 L. plantarum strains had profound antibacterial effects in vitro on the antimicrobial activity assay. A distinct property of LAB is their ability to inhibit bacterial pathogens by producing antimicrobial compounds such as hydrogen peroxide. Lactic acids, acetic acids, and ribosomally-synthesized peptides referred to as bacteriocins have a desirable property for probiotics and a sustainable alternative to antibiotics (28). Our findings are consistent with a study by Lim et al. (27), who reported that L. plantarum and L. fermentum had good microbiological features and were the best inhibitors of uropathogens. However, the other LAB were also good inhibitors. The treatment of UTI generally requires the application of antimicrobial agents, which are also used in the prevention of infection. However, any long-term use of antibiotics will arouse the increased resistance of urinary tract pathogens. The major drugs commonly used for treating UTI in many regions of the world are quinolones, i.e. ciprofloxacin, ampicillin, neomycin, and penicillin. All the Gram-negative uropathogens used in this study displayed susceptibility to ciprofloxacin, except 2 Gram-negative uropathogens, i.e. E. coli and E. fecalis, which exhibited high rates of resistance to kanamycin, ampicillin, neomycin, ciprofloxacin, penicillin, chloramphenicol, erythromycin, vancomycin, and trimethoprim and were sensitive to gentamicin, tetramycin, penicillin, and streptomycin. Nevertheless, in contrast to our results, an unusually high resistant rate, with $67 \%$ of the isolates being resistant to ciprofloxacin and levofloxacin, was reported in Southwest Nigeria (26).

The MICs determined for LAB were found lower than the MIC values suggested as breakpoints for LAB by the EFSA. Accordingly, the strains evaluated in the present study were susceptible to all the antibiotics, as has also been previously reported (29). On the other hand, the only antibiotic resistance detected in the LAB strains was for van- 
comycin MICs $\geq 128 \mathrm{mg} / \mathrm{L}$, which is an intrinsic property of this genus. Klein et al. (30) also reported previously that the resistance to vancomycin detected in Pediococcus, Leuconostoc, and Lactobacillus species might be due to the presence of D-Ala-D-Lactate in their peptidoglycan rather than D-Ala-D-Ala dipeptide. Table 5 shows the antimicrobial activity of the Lactobacillus species against the following test uropathogens: Candida, Pseudomonas, Klebsiella, E. fecalis, and E. coli. In comparison to our results, Mallesha et al. (22) established the antibiogram of LAB species against $E$. faecalis and E. coli and reported that E. faecalis showed the highest GIZ (19 $\mathrm{mm}$ ) against the Gram-positive bacterium Bacillus cereus. In this respect, most of the $L A B$, which came from fruit and vegetable origins and were tested in this work, expressed a broad spectrum of antimicrobial activity against the Gramnegative uropathogens. It is remarkable that a number of strains (11 out of 54 strains) were identified as potential bacteriocin producers. Recently, bacteriocin production ability has been proposed as a key property for the recommendation of the use of probiotic LAB in medicines as an alternative to antibiotics to fight against uropathogen infections in humans, which is similar to what has been proposed for human and farm animal probiotics (31). LAB have thrilling beneficial properties with minimum risk of danger or side effect if used in the treatment of UTI as they inhibit the attack of uropathogenic bacteria by serving as a fighter/preventer against them. Consequently, they may be a sound rationale for probiotics therapy in UTI. Nevertheless, a comprehensive in vivo assessment of the application of these lactobacilli in UTI treatment must be also carried out because in vitro conditions differ greatly from a body metabolism. Therefore, the role of bacteriocin-like substances in vivo remains to be examined, which could be the future perspective of this work. Isolated lactobacilli should also be examined with respect to their potential probiotic characteristics in future investigations.

In this study, a high rate of uropathogen resistance to commercially available antibiotics such as kanamycin, ciprofloxacin, erythromycin, and vancomycin was recorded. Then, as was expected, the majority of the isolated Lactobacillus strains were highly resistant to vancomycin. However, no multiresistant (resistant to more than 2 antibiotics) Lactobacillus strain was found and most of the isolates were susceptible to all the antibiotics examined in this study. Besides resistance to glycopeptides, the 3 L. plantarum strains were highly resistant to streptomycin, while L. acidophilus AS-1 displayed resistance against trimethoprim. On the other hand, the uropathogens sensitivity to isolated lactobacillus species was detected to a large extent.

\section{Acknowledgments}

The authors are grateful to Children hospital, Lahore, Pakistan, for providing the uropathogenic strains and the culture collection of Teagasc food research centre, Moorepark, Fermoy, Co. Cork, Ireland, for providing the indicator strains.

\section{Footnotes}

Authors' Contribution:Concept, design, and writing of the manuscript: Asma Manzoor; critical revision and editing of the manuscript: Sanja Seratlic and Javed Iqbal Qazi; contribution toward the development of the protocol: Ikram ul-Haq and Shahjhan Baig.

Funding/Support:This project was funded by the Higher Education Commission Pakistan as award of Ph.D. scholarship under Indigenous PhD 5000 Fellowship Program Phase-VI.

\section{References}

1. Aslam S, Qazi JI. Isolation of acidophilic lactic acid bacteria antagonistic to microbial contaminants. Pakistan J Zool. 2010;42(5):567-73.

2. Kucheria R, Dasgupta P, Sacks SH, Khan MS, Sheerin NS. Urinary tract infections: new insights into a common problem. Postgrad Med J. 2005;81(952):83-6. doi: 10.1136/pgmj.2004.023036. [PubMed: 15701738]

3. Reid G. Probiotic agents to protect the urogenital tract against infection. Am J Clin Nutr. 2001;73(2 Suppl):437S-43S. [PubMed: $11157354]$

4. Arredondo-Garcia JL, Amabile-Cuevas CF. High resistance prevalence towards ampicillin, co-trimoxazole and ciprofloxacin, among uropathogenic Escherichia coli isolates in Mexico City. $J$ Infect Dev Ctries. 2008;2(5):350-3. [PubMed:19745501]

5. Munoz-Atienza E, Gomez-Sala B, Araujo C, Campanero C, del Campo R, Hernandez PE, et al. Antimicrobial activity, antibiotic susceptibility and virulence factors of Lactic Acid Bacteria of aquatic origin intended for use as probiotics in aquaculture. BMC Microbiol. 2013;13:15. doi:10.1186/1471-2180-13-15. [PubMed: 23347637]

6. Asahara T, Nomoto K, Watanuki M, Yokokura T. Antimicrobial activity of intraurethrally administered probiotic Lactobacillus casei in a murine model of Escherichia coli urinary tract infection. Antimicrob Agents Chemother. 2001;45(6):1751-60.doi:10.1128| AAC.45.6.1751-1760.2001. [PubMed: 11353622]

7. Defoirdt T, Sorgeloos P, Bossier P. Alternatives to antibiotics for the control of bacterial disease in aquaculture. Curr Opin Microbiol. 2011;14(3):251-8. doi: 10.1016/j.mib.2011.03.004. [PubMed: 21489864]

8. Evrard B, Coudeyras S, Dosgilbert A, Charbonnel N, Alame J, Tridon A, et al. Dose-dependent immunomodulation of human dendritic cells by the probiotic Lactobacillus rhamnosus Lcr35. PLoS One. 2011;6(4):e18735. doi: 10.1371/journal.pone.0018735. [PubMed: 21559485]

9. Okereke HC. Antimicrobial properties of probiotic bacteria from various sources. Afr J Biotech. 2012;11(39):9416-21. doi: 10.5897| ajb11.3334.

10. Lakshminarayanan B, Guinane CM, O'Connor PM, Coakley M, Hill C, Stanton C, et al. Isolation and characterization of bacteriocinproducing bacteria from the intestinal microbiota of elderly Irish subjects. J Appl Microbiol. 2013;114(3):886-98. doi: 10.1111/ jam.12085. [PubMed: 23181509]

11. Goldin BR, Gorbach SL. Clinical indications for probiotics: an overview. Clin Infect Dis. 2008;46 Suppl 2:S96-100. doi: 10.1086/523333. [PubMed:18181732]

12. Marja T, Arthur C, Ouwehand, Tiina J, Maarit M. Viability of Lactobacillus paraplantarum DSM 14485 in human gastrointestinal tract and its molecular and biochemical identification after fermented vegetable consumption. Agri Food Sci. 2012;21:182-96.

13. De Man JC, Rogosa M, Sharpe ME. A Medium for the Cultivation of Lactobacilli. J Appl Bacteriol. 1960;23(1):130-5. doi: 10.1111/j.13652672.1960.tb00188.x. 
Manzoor A et al.

14. Holt JG, Krieg NR, Sneath PHA, Staley JT, Williams ST. In: Bergeys Manual of Determinative Bacteriology. Hensyl WR, editor. USA: Williams and Wilkins philadelphia; 2000.

15. Maniatis T, Fritsh EF, Sambrook J. A laboratory manual. New York: Cold Spring Harbor Laboratory; 1982.

16. Randazzo CL, Torriani S, Akkermans AD, de Vos WM, Vaughan EE. Diversity, dynamics, and activity of bacterial communities during production of an artisanal Sicilian cheese as evaluated by 16S rRNA analysis. Appl Environ Microbiol. 2002;68(4):1882-92. [PubMed: 11916708]

17. Lawalata HJ, Sembiring L, Rahayu ES. Molecular identification of lactic acid bacteria producing antimicrobial agents from Bakasang, an Indonesian traditional fermented fish product. Indonesian J Biotech. 2012;16(2):93-9.

18. CLSI. CLSI Performance Standards for Antimicrobial Susceptibility Testing: Twenty-first Informational Supplement M100-S21. USA; Wayne PA. 2011.

19. Milk and milk products determination of the minimal inhibitory concentration (MIC) of antibiotics applicable to bifidobacteria non-enterococcal lactic acid bacteria (LAB). ISO 10932:2010 (IDF 223:2010); 2010. Available from: http://www.iso.org/iso/catalogue_detail. htm?csnumber $=46434$.

20. Pal V, Jamuna M, Jeevaratnam K. Isolation and characterization of bacteriocin producing lactic acid bacteria from a south indian special dosa (Appam) batter. JCulture Collect. 2005;4:53-60.

21. EFSA-FEEDAP. Guidance on the assessment of bacterial susceptibility to antimicrobials of human and veterinary importance. EFSA J. 2012;10:2740-9.

22. Mallesha R, Shylaja D, Selvakumar D, Jagannath JH. Isolation and identification of lactic acid bacteria from raw and fermented products and their antibacterial activity. Recent Res Sci Tech. 2010;2(6):42-6.

23. Ayeni FA, Adeniyi BA, Ogunbanwo ST, Tabasco R, Paarup T, Pelaez $\mathrm{C}$, et al. Inhibition of uropathogens by lactic acid bacteria isolated from dairy foods and cow's intestine in western Nigeria. Arch Microbiol. 2009;191(8):639-48. doi: 10.1007/s00203-009-0492-9.
[PubMed: 19529917]

24. Margolles A, Mayo B, Ruas-Madiedo P. Screening, identification, and characterization 504 of Lactobacillus and Bifidobacterium strains. In: Nomoto K, Salminen S, Lee YK, editors. Handbook of Probiotics and Prebiotics. 505 ed. New Jersey: John Willey and Sons Inc; 2009. pp. 4-43.

25. Boyd MA, Antonio MA, Hillier SL. Comparison of API $50 \mathrm{CH}$ strips to whole-chromosomal DNA probes for identification of Lactobacillus species. J Clin Microbiol. 2005;43(10):5309-11. doi:10.1128/ JCM.43.10.5309-5311.2005. [PubMed:16208005]

26. Sarika AR, Lipton AP, Aishwarya MS. Bacteriocin production by a new isolate of Lactobacillus rhamnosus GP1 under different culture conditions. Adv J Food Sci Technol. 2010;2(5):291-7.

27. Lim IS, Lee HS, Kim WY. The effect of lactic acid bacteria isolates on the urinary tract pathogens to infants in vitro. J Korean Med Sci. 2009;24 Suppl:S57-62. doi: 10.3346/jkms.2009.24.S1.S57. [PubMed: 19194563]

28. Hooton TM, Stamm WE. Diagnosis and treatment of uncomplicated urinary tract infection. Infect Dis Clin North Am. 1997;11(3):551-81. [PubMed: 9378923]

29. Klare I, Konstabel C, Werner G, Huys G, Vankerckhoven V, Kahlmeter G, et al. Antimicrobial susceptibilities of Lactobacillus, Pediococcus and Lactococcus human isolates and cultures intended for probiotic or nutritional use. J Antimicrob Chemother. 2007;59(5):900-12. doi:10.1093/jac/dkm035. [PubMed: 17369278]

30. Klein G, Hallmann C, Casas IA, Abad J, Louwers J, Reuter G. Exclusion of vanA, vanB and vanC type glycopeptide resistance in strains of Lactobacillus reuteri and Lactobacillus rhamnosus used as probiotics by polymerase chain reaction and hybridization methods. J Appl Microbiol. 2000;89(5):815-24. [PubMed: 11119156]

31. O'Shea EF, Cotter PD, Stanton C, Ross RP, Hill C. Production of bioactive substances by intestinal bacteria as a basis for explaining probiotic mechanisms: bacteriocins and conjugated linoleic acid. Int J Food Microbiol. 2012;152(3):189-205. doi:10.1016/j.ijfoodmicro.2011.05.025. [PubMed:21742394] 